\title{
ESGE-ESGENA guideline for quality assurance in reprocessing: Microbiological surveillance testing in endoscopy
}

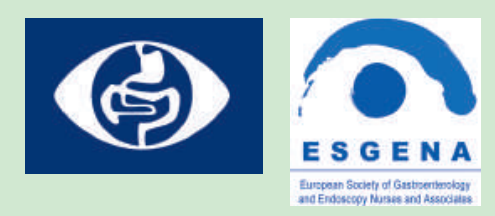

Authors

Institutions
U. Beilenhoff', C. S. Neumann ${ }^{2}$, J. F. Rey ${ }^{3}$, H. Biering ${ }^{4}$, R. Blum ${ }^{5}$, V. Schmidt ${ }^{6}$ and the ESGE Guidelines Committee ${ }^{7}$ Institutions are listed at the end of the guideline.

\section{Bibliography}

DOI $10.1055 / s-2006-945181$

Published ahead of print Endoscopy 2007; 39:

175-181 @ Georg Thieme Verlag KG Stuttgart · New York ISSN 0013-726X

\author{
Contents \\ $\nabla$ \\ 1. Introduction \\ 2. Risk of infections, and potential problem areas during reprocessing \\ 3. Responsibilities \\ 4. Frequency \\ 5. Sampling for routine tests \\ 5.1. Endoscopes \\ 5.2. Final rinse water in washer-disinfectors \\ 5.3. Water supply \\ 6. Cultures/culturing \\ 6.1. Liquid samples from endoscope channels \\ 6.2. Swabs \\ 6.3. Water samples \\ 6.4. Additional tests
}

7. Interpretation of results and corrective measures in case of contamination

7.1. Total microbiological count

7.2. Detection of special microorganisms

8. Management of outbreak of infectious agent

9. References

\section{Introduction}

\section{$\nabla$}

Microbiological surveillance is an important means for evaluating the outcome quality of reprocessing procedures and is an instrument of regular quality control in gastrointestinal endoscopy, whether endoscopic procedures are performed in hospitals, in private clinics or doctors' offices. It is an instrument for detecting and redressing weaknesses and mistakes in the reprocessing procedure and for preventing the transmission of infectious agents through endoscopy. This guideline, from the European Society of Gastrointestinal Endoscopy (ESGE) and the European Society of Gastroenterology and Endoscopy Nurses and Associates (ESGENA), addresses the necessity for microbiological surveillance in endoscopy and provides practical information about testing the quality of the microbiological out- comes of manual and automated reprocessing procedures used in endoscopy.

It is a consensus guideline, prepared in co-operation with endoscopists, microbiologists, hygienists, endoscopy nurses, and representatives from industry.

\section{Aims of this ESGE-ESGENA guideline}

These are:

a) To support individual endoscopy departments in developing local standards and protocols for regular microbiological surveillance

b) To support national societies and official bodies in developing national recommendations and quality assurance programs for hygiene and infection control in gastrointestinal endoscopy 
- Inadequate cleaning (e.g. inadequate manual cleaning and brushing of endoscope channels)

- Contaminated cleaning accessories (e.g. cleaning brushes)

- Use of unsuitable or incompatible detergents and disinfectants

- Inadequate concentrations and contact time of agents

- Contaminated or time-expired solutions

- Contaminated rinsing water

- Fixed organic material (biofilm) in endoscopes, water pipes, containers, or washer-disinfectors

- Use of nonsterile accessories in invasive diagnosis and treatment (e.g. nonsterile biopsy forceps, polypectomy snares)

- Inadequate reprocessing of water bottles (e. g. no sterilization)

- Use of tap water in water bottles

b. Inadequate transport and storage of endoscopes

- Insufficient drying before storage (e.g. Pseudomonas spp.)

- Inappropriate storage conditions

c. Contaminated or defective washer-disinfector

- Contaminated pipes, containers, etc.

- Contaminated final rinsing water

- Mechanical/electronic defects of washer-disinfector

- Incorrect use of washer-disinfector (e. g. wrong connections)

- Lack of regular maintenance of washer-disinfector according to manufacturer's recommendations

d. Design limitations and damaged endoscopes

- Small lumina, branched channels, not accessible to cleaning brushes

- Damage to the surfaces (internal and external) of the endoscope, providing potential for contamination

e. Contaminated water in the endoscopy unit

- Contaminated main water pipes/supply

- Contaminated or inadequate water supply systems (filtration etc.)

\section{Risk of infections and potential problem areas during reprocessing \\ $\nabla$}

Endoscopic procedures have become an essential tool in the diagnosis and treatment of gastrointestinal diseases, and every patient has the right to be examined and treated without risk of transmission of infectious agents or complications that may result from inadequate reprocessing of endoscopes and endoscopic accessories [1].

Since the late 1970s there have been sporadic reports of nosocomial infections linked to endoscopic procedures. Bacterial infections have been acquired during endoscopy, caused for example by Salmonella spp., Helicobacter pylori and Pseudomonas spp. [2-6]. Viral diseases such as hepatitis B and $C$ have also been transmitted during endoscopy [7-8]. The majority of documented cases were caused by non-compliance with national and international reprocessing guidelines [2-8].

Manual cleaning including brushing is the first and most important step in reprocessing flexible endoscopes $[1,9,10]$, regardless of whether an automated system is used. Non-cleaned or insufficiently cleaned endoscope channels promote the formation of microbial plaques and biofilms. Organic material which is not removed by manual brushing can additionally be fixed by aldehydes and promote the growth of organisms. Manual cleaning must include all accessible endoscope channels, all valve ports, the outer surface, and parts that are difficult to access such as the bridge elevator. Therefore, thorough cleaning is a prerequisite for adequate disinfection, regardless of whether the endoscope is reprocessed manually or in an automatic washer-disinfector.

In addition to the endoscopes themselves, water bottles can be a source of endoscope contamination. This can be caused by inadequate cleaning of water bottles, lack of sterilization or use of tap water instead of sterile water [11]. Therefore, testing of water bottles should be part of regular quality control.
As the design of endoscopes varies depending on the manufacturer, it is essential that staff is familiar with the design and construction of all the equipment in order to ensure safe and adequate cleaning and disinfection.

- Table 1 presents a summary of areas of weakness and deficiencies with regard to endoscope reprocessing.

\section{Responsibilities}

$\nabla$

A quality assurance program with regular microbiological surveillance should be established for endoscopy rooms, whether endoscopy is carried out in hospitals, private clinics, or doctors' offices.

The clinical service providers have a duty of care to provide hygiene supervision and to carry out microbiological surveillance. Furthermore, every professional also has a duty of care to comply with the relevant national recommendations and regulations.

The collection, culturing, and interpretation of test results should be performed in close co-operation with the endoscopists, endoscopy nurses, hygienists and appropriate microbiology personnel/microbiologists. All test details (including test media, method of collecting samples, culture, and interpretation) should be discussed with the relevant microbiological authorities prior to testing.

\section{Frequency}

Depending on the reprocessing procedure (manual or automated), routine quality assurance of the whole endoscope reprocessing system must be established. Routine testing can cover periodic microbiological surveillance of endoscopes, washer-disinfectors, accessories, and the water supply used in endoscopy. 


\begin{tabular}{|c|c|c|}
\hline Test area/material & Test method & Standard \\
\hline $\begin{array}{l}\text { Each endoscope } \\
\text { channel }\end{array}$ & $\begin{array}{l}\text { Flushing or rinsing of: } \\
\text { - Suction/biopsy channel } \\
\text { - Water channel } \\
\text { - Air channel } \\
\text { - Additional rinsing channels } \\
\text { - Elevator channel on duodeno- } \\
\text { scopes }\end{array}$ & $\begin{array}{l}\text { - Fill a sterile syringe with } 20 \mathrm{ml} \text { sterile saline } \\
\text { - Connect the syringe to the entry port of each } \\
\text { channel } \\
\text { - Ensure that the connection permits complete } \\
\text { flushing of the whole channel } \\
\text { - Adequate connectors should be used in order to } \\
\text { guarantee correct rinsing } \\
\text { - Collect the fluid in a sterile container }\end{array}$ \\
\hline Outer surfaces & $\begin{array}{l}\text { Swabs from e. g.: } \\
\text { - Distal end } \\
\text { - Valve ports } \\
\text { - Bridge elevator }\end{array}$ & $\begin{array}{l}\text { - Use sterile swabs, moistened with sterile saline } \\
\text { with or without appropriate neutralizer } \\
\text { - Take swabs from each separate part of the } \\
\text { endoscope } \\
\text { - Put each swab separately in a suitable medium and } \\
\text { container (eg. Tryptic Soy Broth, containing } \\
\text { neutralizer) }\end{array}$ \\
\hline Water bottle & Liquid sample & $\begin{array}{l}\text { - Water bottle ready for use should be tested } \\
\text { - Sample volume: } 2 \times 100 \mathrm{ml} \\
\text { - Adequate connectors should be used in order to } \\
\text { take liquid samples from the water bottle via the } \\
\text { connection tube of the water bottle } \\
\text { - Use the appropriate and adequate connector and a } \\
\text { sterile syringe to collect liquid samples from the } \\
\text { water bottle }\end{array}$ \\
\hline Final rinse water & Water sample & $\begin{array}{l}\text { - Use a sterile syringe } \\
\text { - Collect the water in a sterile container } \\
\text { - Sample volume: } 2 \times 100 \mathrm{ml}\end{array}$ \\
\hline
\end{tabular}

Table 2 Sampling methods for testing the quality of reprocessing of endoscopes
National guidelines and laws on hygiene and infection control in gastrointestinal endoscopy vary from country to country $[9,10]$. Consequently the frequency of microbiological surveillance and recommended test procedures differs across Europe (see Appendix). This guideline will therefore need to be modified locally in compliance with the appropriate national regulations.

As a point of reference, the ESGE-ESGENA guideline committee recommends routine testing at intervals no longer than 3 months.

Endoscopes. Depending on the number of endoscopes in use, it may be impractical to test each endoscope at each occasion. Therefore a sample of each type/series should be tested at each sampling session in rotation, making sure that at the end of the year each endoscope has been sampled at least once.

Water supply. Microbiological surveillance of the final rinse water used in endoscopy should be carried out on the same day as the microbiological surveillance of the endoscopes, in order to assure the testing of the complete reprocessing cycle.

Washer-disinfectors. In the case of automated endoscope reprocessing, validation of the whole procedure is necessary to ensure that it complies with the requirements of the European Standard, prEN ISO 15883 parts 1, 4 and 5 [13]. The ESGE-ESGENA guideline for process validation and for routine testing for endoscope reprocessing in washer-disinfectors should be considered in this regard [14].

The microbiologists should record the data and make a simple trend analysis to see if any contamination detected increased or decreased between tests in order to identify any changing circumstances before a potential outbreak.

\section{Sampling for routine tests}

\subsection{Endoscopes}

Microbiological testing of endoscopes should cover:

- all channels

the outer surfaces, and

- the connected water bottle.

A sampling plan for each endoscope type has to be established, that takes into account the critical parts of each type.

Sterile saline $0.9 \%$ is the most popular test solution. Depending on requirements, a dose of neutralizer can be added to the saline solution (or into the sterile sampling container) in order to neutralize any traces of chemicals which may limit detection of microorganisms. Reports on in vitro efficacy tests of the disinfectant used may serve as indicators for the choice of an appropriate neutralizer.

To avoid contamination from the environment, the collection of samples must be done under aseptic conditions.

Method of sampling. Standard testing of the endoscope includes collection of:

a) liquid samples from endoscope channels,

b) swabs from outer surfaces, and

c) liquid samples from water bottles.

a. Liquid samples from endoscope channels. Flush the appropriate channels with $20 \mathrm{ml}$ sterile saline and collect the liquid in a sterile container (see $\bullet$ Table 2 ).

Note:

- Because of the complex construction of endoscope channels, each channel should be tested separately.

- Adequate connectors should be used to ensure the complete and separate flushing of each channel.

- The endoscope manufacturer should give clear instructions on how to connect and test each channel.

- Because of its small lumen, the elevator channel of duodenoscopes should be tested by flushing with $5 \mathrm{ml}$ sterile saline with or without an appropriate neutralizer. 
Table 3 Indicator organisms for quality control

\begin{tabular}{|c|c|c|}
\hline $\begin{array}{l}\text { Organisms identified } \\
\text { in microbiological } \\
\text { tests }\end{array}$ & Indication of origin & Troubleshooting \\
\hline \multirow[t]{2}{*}{$\begin{array}{l}\text { Escherichia coli, entero- } \\
\text { cocci and Enterobacte- } \\
\text { riaceae }\end{array}$} & $\begin{array}{l}\text { A: Insufficient cleaning and/or disinfection procedures, e. g.: } \\
\text { - No brushing } \\
\text { - Inadequate concentrations or exposure times of process } \\
\text { chemicals }\end{array}$ & $\begin{array}{l}\text { A: Review whole reprocessing cycle with special emphasis } \\
\text { on manual cleaning }\end{array}$ \\
\hline & $\begin{array}{l}\text { B: Mechanical or electronic defects of washer-disinfector, } \\
\text { e. g.: } \\
\text { - Incorrect amounts and/or concentration of processing } \\
\text { chemicals } \\
\text { - Design flaws of washer-disinfector, with dead volumes }\end{array}$ & B: Initiate full maintenance of washer-disinfector \\
\hline $\begin{array}{l}\text { Pseudomonas aerugino- } \\
\text { sa and other gram-neg- } \\
\text { ative nonfermenters }\end{array}$ & $\begin{array}{l}\text { A: } \\
\text { - Insufficient final rinsing } \\
\text { - Contamination of final rinsing water } \\
\text { - Contamination of washer-disinfector due to mechanical or } \\
\text { electronic defects } \\
\text { - Contamination of filter systems } \\
\text { - Design flaws of washer-disinfector with dead volumes }\end{array}$ & $\begin{array}{l}\text { A: Review water supply systems and procedures: } \\
\text { - Water quality } \\
\text { - Manual and/or washer-disinfector rinsing } \\
\text { - Initiate full maintenance of washer-disinfector and } \\
\text { filtration systems } \\
\text { - Initiate autodisinfection cycle according to manufac- } \\
\text { turer's instructions (thermal disinfection is preferred) }\end{array}$ \\
\hline & B: Insufficient drying of endoscopes before storage & $\begin{array}{l}\text { B: Review drying procedures before storage, and } \\
\text { ventilation of storage facilities }\end{array}$ \\
\hline \multirow[t]{2}{*}{$\begin{array}{l}\text { Staphyloccus aureus, } \\
\text { Staphylococcus epider- } \\
\text { midis }\end{array}$} & $\begin{array}{l}\text { Recontamination of endoscopes due to: } \\
\text { - Inadequate storage and transport } \\
\text { - Inadequate hand hygiene }\end{array}$ & $\begin{array}{l}\text { Review of hygiene arrangement for storage, transport and } \\
\text { of manual handling }\end{array}$ \\
\hline & Contamination from sampling & Repeat sampling \\
\hline $\begin{array}{l}\text { Atypical mycobacteria } \\
\text { Legionella organisms }\end{array}$ & Contamination of washer-disinfector and water system & $\begin{array}{l}\text { Review water supply systems and procedures: } \\
\text { - Manual and/or washer-disinfector rinsing } \\
\text { - Initiate autodisinfection cycle according to manufac- } \\
\text { turer's instruction (thermal disinfection is preferred) } \\
\text { - Initiate full maintenance of washer-disinfector and } \\
\text { filtration systems }\end{array}$ \\
\hline
\end{tabular}

b. Swabs from the outer surfaces of the endoscope. These swabs are taken to test the adequacy of cleaning and disinfection. The method is described in $\bullet$ Table 2 .

c. Liquid samples from water bottles. Water samples should be taken from water bottles at the end of the defined application period (see $\bullet$ Table 2 ).

\subsection{Final rinse water of washer-disinfectors}

Depending on the design of the washer-disinfector, the options for collecting samples may vary. Irrespective of the type of washer-disinfector, the complete reprocessing cycle should be tested. Manufacturers should provide advice regarding appropriate means of microbiological sampling. A sample of $2 \times 100 \mathrm{ml}$ should be taken from the final rinse water.

\subsection{Water supply}

Take water samples according to national recommendations for testing of tap water.

\section{Cultures|culturing}

The samples should be processed shortly after collection. If any delay is likely, the samples should be refrigerated (e.g. for transportation).

\subsection{Liquid samples from endoscope channels}

Total microbiological count. Take $1 \mathrm{ml}$ of the sample and place on an appropriate number of plates (depending on plate size) of a complete medium (e.g. Tryptic Soy Agar [TSA]). Incubate for $48 \mathrm{~h}$ at $30^{\circ} \mathrm{C}$.

Depending on the required detection limit, another $10 \mathrm{ml}$ of the same sample can be filtered (pore diameter not greater than $0.45 \mu \mathrm{m}$ ). The filter is incubated on an agar plate containing a complete medium (e.g. TSA) at $30^{\circ} \mathrm{C}$ for $48 \mathrm{~h}$.

Detection of special microorganisms.

Enterobacteriaceae, Pseudomonas aeruginosa and staphylococci should be tested as indicator organisms. We would recommend that not only the final rinse water but also the endoscopes should be tested for atypical mycobacteria. This would ensure that the whole system is tested according to prEN ISO 15883-4. Add the same volume of double-concentrated Tryptic Soy Broth (TSB) to the rest of the sample and incubate it at $37^{\circ} \mathrm{C}$ for $48 \mathrm{~h}$. Double concentrated MADC broth and incubation at $37^{\circ} \mathrm{C}$ for 21 days should be used if a test for mycobacteria is deemed appropriate. Streak out on selective agar plates and incubate for an appropriate time and temperature according to the manufacturer's instructions, for example, using:

- Violet Red Bile Dextrose (VRBD) agar as a selective medium for detection of Enterobacteriaceae

- Cetrimid agar for detection of Pseudomonas aeruginosa

- Baird-Parker agar for detection of staphylococci

- Middlebrook agar for detection of mycobacteria

Further identification tests (e.g. commercially available biochemical test systems for bacteria or acid-fast stain for mycobacteria) may be necessary to confirm the presence of certain groups or species of bacteria. 


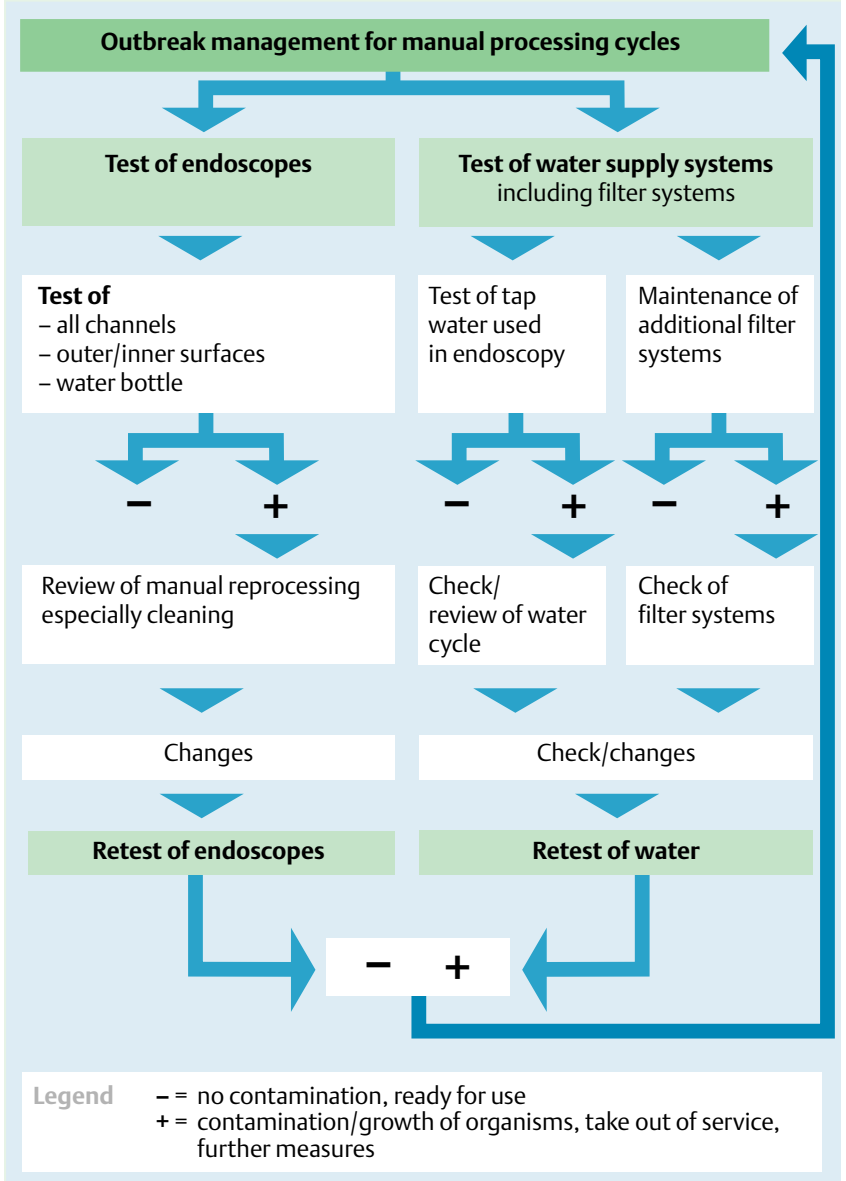

Figure 1 Management of outbreak of infectious agents in manual reprocessing cycles.

\subsection{Swabs}

Extract the swab in $10 \mathrm{ml}$ of TSB plus neutralizer, using a vortex. Detection of special microorganisms. Incubate the $10 \mathrm{ml}$ volume at $37^{\circ} \mathrm{C}$ in an incubator for $48 \mathrm{~h}$. Streak out on selective agar plates and incubate for an appropriate time and temperature, according to the manufacturer's instructions (see section 6.1.)

\subsection{Water samples (from water bottle + final rinse water)}

According to the European Standard, prEN ISO 15883-4 the final rinse water should be free of Pseudomonas aeruginosa, atypical mycobacteria and Legionellae spp.

The aerobic total microbial count is determined by filtration $(0.45 \mu \mathrm{m}$ pore size $)$ of $10 \mathrm{ml}$ and $100 \mathrm{ml}$ water samples. The sample is incubated at $30 \pm 2{ }^{\circ} \mathrm{C}$ on $\mathrm{R}_{2} \mathrm{~A}$ medium or another appropriate low nutrient medium for 5 days. The colonies are counted, and the type of microbe is determined by subculture on appropriate selective media and/or standard identification techniques (e.g. commercially available biochemical test systems) are used. For the detection of mycobacteria, Middlebrook 7H10 agar should be used and incubated at $37^{\circ} \mathrm{C}$ for up to 21 days.

The methodology of the International Standard ISO 11731 can be used for the detection of Legionella spp.

For higher sensitivity in the detection of indicator organisms, an enrichment technique can be used, as follows. A $100 \mathrm{ml}$ water sample is added to $100 \mathrm{ml}$ double strength TSB and incubated at $37^{\circ} \mathrm{C}$ for $48 \mathrm{~h}$. The culture is then streaked onto selective media (see section 6.1) for identification of any grown organisms. For the detection of atypical mycobacteria, double strength MADC broth (at $37^{\circ} \mathrm{C}$ for 21 days) and subculture on Middlebrook $7 \mathrm{H} 10$ agar (at $37^{\circ} \mathrm{C}$ for 21 days) should be used.

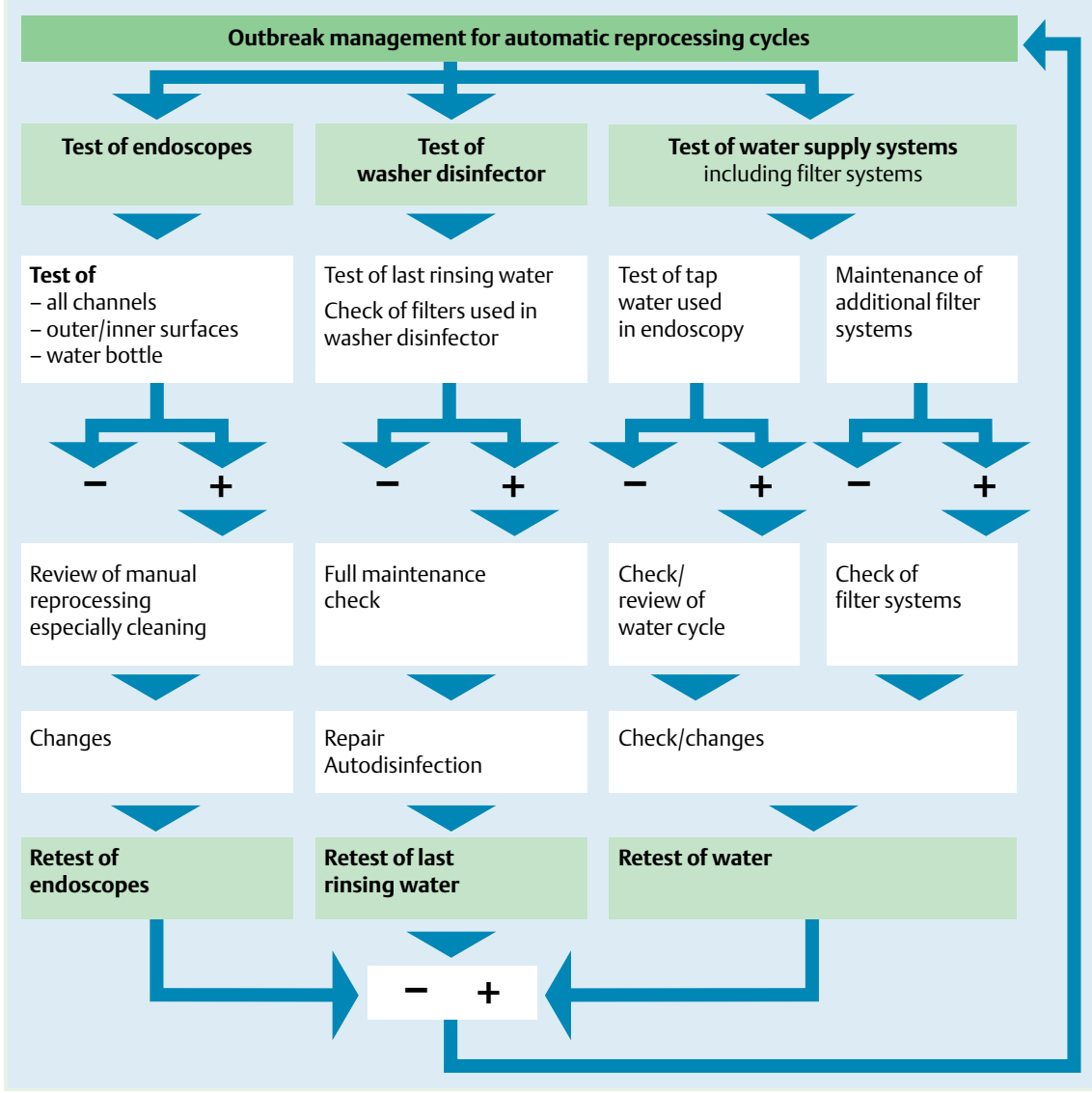

Figure 2 Management of outbreak of infectious agents in automated reprocessing cycles. 


\subsection{Additional tests}

If clinical or epidemiological data suggest the transmission of infectious agents, in addition to the routine sampling, the test methods should focus on the suspicious organism (see section 8, Management of outbreak of infectious agent).

\section{Interpretation of results and corrective meas- ures in case of contamination}

A variety of bacteria and viruses have been associated with endoscopy-related transmission of infectious agents [2-8]. The detection of viruses is complex, time-consuming and expensive, especially that of intact, infective viruses. Therefore routine microbiological surveillance does not include viruses.

In the case of regular microbiological surveillance, it is not necessary to test for all possible bacteria. A number of organisms can be used as indicators of weaknesses or mistakes in the reprocessing procedure. An overview is given in Table 3.

\subsection{Total microbiological count}

a. Liquid samples from endoscope channels. The maximal total count should be $<20 \mathrm{cfu} / \mathrm{channel}$. It should be calculated taking into account the amount of saline used to rinse the channel. Indicator organisms should not be found at any time.

b. Swabs. Cultures taken from swabs should be focused on the growth of indicator organisms (see section 7.2. and $\bullet$ Table 3). Quantification of microorganisms is not recommended.

c. Water samples. The maximum total count should be should be $<10 / 100 \mathrm{cfu} / \mathrm{ml}$. Indicator organisms should not be found at any time.

\subsection{Detection of special microorganisms}

A criterion for acceptability is the absence of growth of indicator organisms (see Table 3 ).

\section{Management of outbreak of infectious agent} $\nabla$

In the case of manual reprocessing, the endoscopes and water used in endoscopy rooms must be tested ( $\bullet$ Figure $\mathbf{1}$ ).

In the case of automated reprocessing, the endoscopes, washerdisinfector, and the water used in endoscopy must be tested at the same time, in order to identify the cause of infection ( $\mathbf{F i g}$ ure 2).

If any contamination is found, it is the responsibility of the clinical service provider to take the suspect piece of equipment out of service (e.g. endoscopes, washer-disinfector, accessories, etc), until corrective actions have been taken and satisfactory results have been achieved [14].

Institutions

ESGENA Treasurer, Ulm, Germany

2 ESGENA President, Clinical Investigation Unit, City Hospital NHS Trust, Birmingham, UK

3 ESGE Guidelines Committee Chairman, Institute A. Tzanck, Saint Laurent du Var, France

${ }^{4}$ R, D\&E Health Care EMEA, Ecolab GmbH \& Co OHG, Düsseldorf, Germany

BU Endoscopy Reprocessing Systems, Olympus Medical Systems Europa Gmbh, Hamburg, Germany

${ }^{6}$ Microbiology and Hygiene Department, Chemische Fabrik Dr. Weigert GmbH \& Co. KG, Hamburg, Germany

\section{References}

1 ESGE-ESGENA Guideline Committee. Guidelines on cleaning and disinfection in gastrointestinal endoscopy - update 1999. Endoscopy 2000; 32: 77-83

2 Spach DH, Silverstein FE, Stamm WE. Transmission of infection by gastrointestinal endoscopy. Ann Intern Med 1993; 118: 117-128

3 Ayliffe GA. Nosocomial infections associated with endoscopy. In: Mayhall CG (ed). Hospital epidemiology and infection control. Baltimore: Williams \& Wilkins, 1995: 680-693

4 Cowen $A E$. The clinical risks of infections associated with endoscopy. Can J Gastroenterol 2001; 15: 321 - 331

5 Langenberg W, Rauws EA, Oudbier JH, Tytgat GN. Patient to patient transmission of Campylobacter pylori by fiberoptic gastroduodenoscopy and biopsy. J Infect Dis 1990; 161: 507-511

6 Moayyedi P, Lynch D, Axon A. Pseudomonas and endoscopy. Endoscopy 1994; 26: $554-558$

7 Bronowicki JP, Vernard V, Botte C et al. Patient-to-patient transmission of hepatitis C virus during colonoscopy. N Engl J Med 1997; 337: 237 240

8 Birnie GG, Quigley EM, Clements GB et al. Endoscopic transmission of hepatitis B virus. Gut 1983; 24: 171 - 174

9 Rey JF, Kruse A. Cleaning and disinfection in Europe according to the endoscopic societies' guidelines. Endoscopy 2003; 35: 878-881

10 Leiss $O$, Beilenhoff $U$, Bader L et al. Reprocessing of flexible endoscopes and endoscopic accessories - an international comparison of guidelines. Z Gastroenterol 2002; 40: 531 - 542

11 Bader L, Blumenstock G, Birkner B. HYGEA (Hygiene in der Gastroenterologie-Endoskop-Aufbereitung): Studie zur Qualität der Aufbereitung von flexiblen Endoskopen in Klinik und Praxis [HYGEA (Hygiene in gastroenterology - endoscope reprocessing): Study on quality of reprocessing flexible endoscopes in hospitals and in the practice setting]. Z Gastroenterol 2002; 40: 157 - 170

12 RKI (Robert Koch Institut). Empfehlungen der Kommission für Krankenhaushygiene und Infektionsprävention beim Robert-Koch-Insitut zu den Anforderungen an die Hygiene bei der Aufbereitung flexibler Endoskope und endoskopischen Zusatzinstrumentariums. Bundesgesundheitsblatt 2002; 45: 395-411

13 prEN ISO 15883

14 ESGE-ESGENA-Guideline Commitee. ESGE-ESGENA guideline for process validation and for routine tests for reprocessing endoscopes in washer disinfectors, according to prEN ISO 15883, parts 1, 4 and 5. Endoscopy; 2007; 39: $85-94$

\section{Appendix}

\section{$\nabla$}

A survey was performed in July 2006 in the ESGE and ESGENA membership countries, and there were replies from 20 countries. In the majority of countries endoscopes are reprocessed in automated systems (18/20). Among the 20 countries, 13 have national guidelines on reprocessing of endoscopes and accessories, while national guidelines on microbiological surveillance are available in eight of the 20 (see Table 1 ). Microbiological testing varies greatly between countries in 12 of the 20 . Many countries recommend testing every 3 months (see Table $\bullet$ 5). 


\begin{tabular}{|c|c|c|c|c|}
\hline Country & $\begin{array}{l}\text { Manual reproces- } \\
\text { sing of endoscopes }\end{array}$ & $\begin{array}{l}\text { Automated } \\
\text { reprocessing of } \\
\text { endoscopes }\end{array}$ & $\begin{array}{l}\text { National guide- } \\
\text { lines on endo- } \\
\text { scopes and acces- } \\
\text { sories }\end{array}$ & $\begin{array}{l}\text { National guideline } \\
\text { on microbiological } \\
\text { surveillance }\end{array}$ \\
\hline Austria & & $x$ & $x$ & $x$ \\
\hline Belgium & $x$ & $x$ & $x$ & \\
\hline Croatia & & $x$ & & $x$ \\
\hline Czech Republic & $\mathrm{x}$ & & & \\
\hline Denmark & & $x$ & & \\
\hline Finland & & $x$ & $\mathrm{x}$ & \\
\hline France & & $x$ & $x$ & $x$ \\
\hline Germany & & $x$ & $\mathrm{x}$ & $\mathrm{x}$ \\
\hline Iceland & & $x$ & & \\
\hline Italy & $x$ & $x$ & $x$ & \\
\hline Jordan & $x$ & & $x$ & \\
\hline Luxembourg & & $x$ & & \\
\hline Monaco & & $x$ & $x$ & $x$ \\
\hline Netherlands & & $x$ & $x$ & \\
\hline Norway & & $x$ & & \\
\hline Slovenia & & $x$ & $x$ & $x$ \\
\hline Spain & & $x$ & & \\
\hline Sweden & & $x$ & $x$ & $x$ \\
\hline Switzerland & & $x$ & $x$ & \\
\hline UK & & $x$ & $x$ & $x$ \\
\hline Total & 4 & 18 & 13 & 8 \\
\hline
\end{tabular}

\begin{tabular}{|c|c|c|c|}
\hline \multirow[t]{2}{*}{ Country } & \multicolumn{3}{|c|}{ Interval between tests, months (except where indicated) } \\
\hline & Endoscopes & Automatic washer-disinfectors & Water \\
\hline Austria & 12 & 12 & NA \\
\hline Croatia & 3 & 3 & 3 \\
\hline Denmark & 1 & 6 & 0 \\
\hline France & 12 & 3 & 1 \\
\hline Germany & 3 & 3 & 3 \\
\hline Italy & 6 & 6 & 12 \\
\hline Monaco & 1 & 1 & 1 \\
\hline Slovenia & Individual tests & Individual tests & 6 \\
\hline Spain & 3 & No & No \\
\hline Sweden & 3 & 3 & No \\
\hline Switzerland & 3 & NA & NA \\
\hline UK & No tests of endoscopes & $\begin{array}{l}\text { According to manufacturers' } \\
\text { recommendations }\end{array}$ & Once a week \\
\hline
\end{tabular}

Table 4 National variations in reprocessing of endoscopic equipment and provision of guidelines

Table 5 National variations in testing intervals for routine microbiological surveillance 